first aid to persons unable to swim were shown, as well as the methods of resuscitation of the apparently drowned. It so happened that a stranger did actially jump or fall into the water during the demonstration, so that a genuine piece of live-saving work was witnessed. It is the intention of the authorities here to establish, after the model of the British Royal Humane Society, an institution for first aid in accidents on the water, shipwreck, floods, suicidal attempts, and the like. Among the papers read at the Congress were some of great interest. One of the subjects discussed was the relation of explosions in mines to the composition of the explosives used for blasting; whilst in some countries a variety of explosives may be had which produce harmless by-products, in Austria the Government does not allow any of the newer preparations to be used, dynamite and gun-cotton only being at the disposal of the industry. A collection of lifesaving apparatus for mines, consisting of a fire-proof suit of clothes (asbestos-linen), with an airtight headpiece, an apparatus for generation of oxygen and removal of $\mathrm{CO}_{2}$ fitted with electric searchlights, was exhibited by the Austrian State Mines Administration in connexion with this paper. A similar exhibit of the Vienna Fire Brigade was also shown, together with some electric machines and ladders used to climb into smoke-filled or burning buildings.

The danger of transmission of Asiatic epidemics into European countries was well illustrated in the paper by Dr. Kobler, the head of the sanitary department of Bosnia and Herzegovina. The prevention of such epidemics has become a much more difficult task since the completion of the Hedjas railway between the holy places and Damascus. Formerly the pilgrims had to spend many weeks on the road, so that a natural quarantine was obtained. Now the journey lasts a few days. The sanitary conditions of the country are most rudimentary, and all European States with Mohammedan population have erected special pilgrim stations on the frontier's, where suspicious cases can be kept under observation.

The prevention of loss of life in aeronautics was dis cussed in a paper by M. Hinterstoisses. He maintained that smoking should be absolutely prohibited in all localities pertaining to airships; that no spectators should como near an airship or aeroplane intending to descend; that a doctor should always be present at the "air port" or on the airship; and that a transportable first-aid outfit with medicines and splints, as well as an apparatus for extinguishing a fire, should always be at hand there.

Much interest was evoked by the paper on first aid in mountaineering, which has been organized by the German and Austrian Alpine Society at considerable outlay. A network of ambulance stations has been established all over the mountains in the two countries. Over 200 firstaid outfits have been distributed amongst these stations; the services of a large number of voluntary or paid helpers have been secured for cases of emergency, for the saving of living persons, or for search parties to recover the bodies of climbers killed in the mountains. Each station is fitted out with one box for first aid with splints and medicines, one pair of stretchers or a hammock, several packots of bandages, several small first-aid outfits for the authorized mountain guides (who have to carry them on every trip), probes for searching avalanches (these have proved exceedingly useful), and rope-ladders and ropes. A knowledge of first-aid work is spreading rapidly, and the international Alpine danger signal has been adopted by many societies and clubs. It should be added that the society defrays for its members all costs arising out of an accident or an expedition for help. Much good has been done by the instruction (in special tirst-aid classes) of the guides in all matters pertaining to mountain accidents. They are taught how to treat injuries, insect bites, snow blindness, glacier disease, how to apply a splint, to conduct artificial respiration, and how to prepare stretchers.

The prevention of loss of life in the large ships of modern times was discussed by Professor Flamm. He advised the formation of watertight compartments in the long axis as well as in the transverse diameter, with due respect to the stability of the ship. The number of the life boats and their capacity ought to depend on the number of persons on board not on the tonnage of the ship, and need not be brought into relation with the watertight compart. ments. Wireless telegraphy, as well as careful considera.

tion of the ballast and fuel, and the fireproof storage of the latter, were, he said, indispensable in a modern ship. Medical help should be available on every ship, one doctor at least being provided for each five hundred persons on board.

(To be continued.)

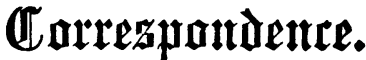

GREAT TENACITY OF LIFE.

SiR,-This week I read in the Journal of June 21st, 1913 , p. 1320, the case illustrating great tenacity of life, by Dr. Turnbull. But the day before yesterday the following appeared in the Sydney Morning Herald (July 24th), and it is sufficiently noteworthy to induce me to send it to you :

Wellington (N.Z.), Wednesday.

J. Millar, an employee of the electrical works at Timaru, fell from the top of a lighting pole in February, striking his head on the concrete kerb footpath and fracturing his skull. His other injuries were a pelvis broken in three places, five ribs broken, one piercing the kidney, breast bone broken, left arm broken in three piaces, and shock. He lay in the hospital for five days unconscious, and the case was deemed hopeless. Yet Millar has now resumed work, and says he feels as well as ever.

Comparing the two cases, then, we have:

Dr. Turnbull's Case.

1. A fractured skull.

1. Fractured skull.

xtensive fracture of the 2. Five ribs fracture$$
\text { ribs. }
$$

4. Pulping of the kidney and lesions in the vicinity of the solar plexus.

5. Result-Death. -I am, etc., places. places.

7. Shock.
3. Pulping of the spleen.

3. One kidney pierced.

4. Pelvis broken in

6. Breast bone broken

6. Left arm broken in three

8. Has resumed work, and says he feels as well as ever!

Department of Physiology, Medical School,

University of sydney,

\section{IDIOPATHIC ANASARCA.}

Sir,-I have read carefully, and with much interest, the report in our JoURNAL of the proceedings at the International Medical Congress, but was disappointed in not finding any reference to the discovery of a new diseaso by a Russian physician, called by him "idiopathic anasarca," which discovery was noticed in the Epitome of Current Medical Literature, and the importance of which discovery $I$ endeavoured to emphasize in a letter to the Journal. No one seems to have appreciated the value of the discovery except the writer of the notice of it in the Epitome, and, seeing that it was not noticed at the Inter. national Medical Congress, I should like once more to call the attention of your readers to the symptoms, which, I believe, will be found to be associated with the cause of what are called sudden deaths, which are becoming so common even in our own profession. It is a symptom which I have recognized for years in my own person, and I am gratified to know that another has recognized it. In my former letter I pointed out that "idiopathic" was a term used as a cloak for ignorance.

In a medical vocabulary published in 1836, "idiopathic" is said to be "A disease not consequent on another, but originating by itself," and "anasarca" as "Dropsy in tho integuments of the body; a genus of the Ord. Intumes centiae; Cl. Cachexiae, of Cullen's Nosology." Not having been taught (when a student at Edinburgh University) the views current as to the dropsy now associated with the name of Dr. Bright, I turned up Craigie's Practice of Physic, of which I happened to have a copy. Writing on inflammation of the kidney, he says: "The acute form of the disorder has been usually distinguished into two varieties, according to the supposed nature of the exciting cause-the idiopathic, or that originating spontaneously, and without the presence of any mechanical irritation ; and the symptomatic, or that which is induced more or less immediately by the irritation of one or moro urinary concretions or sandy particles in the pelvis, or in any of the infundibula of the gland. The first variety is supposed to be rare, the second greatly more common." 
The supposed rarity of the idiopathic form need not astonish us, seeing that ". idiopatliic anasarca" of the Russian physician is not yet recognized by the profession, or noticed at even an "International Medical Congress."

Under " Granular degeneration of the kidneys," Craigie says: "These circumstances (finding an inflammatory state of some serous membranes) led Dr. Blackall to regard the human frame as in an inflammatory state while the urine is albuminous, and to regard all those cases of dropsy in which this state of urine is observed as originating in, or connected with, inflammation, and hence to have recourse to antiphlogistic remedies." And again, he says, "Although the general result of the researches of Dr. Blackall was to establish a clear and evident distinction, both in pathology and treatment, between dropsies with inflammatory symptoms and those without such symptoms, yet no connexion was established between the serous state of the urine and any morbid condition of the kidney. This was accomplished, however, in 1827, by Dr. Bright.

"It was partially known to Morgagni that the kidneys were liable, in anasarca, to a certain change in structure, in which their two component parts, the cortical or secreting and the tubular or excreting, became, as it were, blended or confused together, and often contained small serous cysts or vessels."

Here it will be observed that the word "anasarca" is used as synonymous with "dropsy," but I hope to prove that the anasarca is entirely different from dropsy. Dr. Craigie says :

The general correctness of the inference regarding the con nexion between serous urine and more or less disease of the kidney was speedily confirmed by Dr. Christison, Dr. James C. Gregory in this country, by Dr. Osborne in Ireland, and by Solon and Rayer in France.

The facts ascertained by these observers must be allowed, not only to have established the fact of the connexion between albuminous urine and different degrees and stages of disease of the kidney, but to have thrown a considerable degree of light upon the disease in general, and to have shown that dropsy, as well as the several inflammatory and congestive states of the disorder, are mere secondary or symptomatic effects of the change in the structure of the kidneys and the corresponding change in the structure of the kidneys
change in the function of these glands.

Professor Grainger Stewart was a pupil of Christison, and wrote a big book on Bright's disease. When he was pathologist to the infirmary in Edinburgh $I$ was his assistant, and from the symptoms in any case of Bright's disease it was easy to tell what the kidney would be like, but all our pathology did not help us to cure or even prevent that disease, to which Grainger Stewart himself fell a victim.

The profession now recognizes the fact that a pulse of high tension is associated with Bright's disease and precedes the actual appearance of albumin in the urine, but the cause of the increased tension is still unrecognized. Professor Laycock, a contemporary of Christison and Grainger Stewart, taught us that the dropsy in Bright's disease was a neurosis, but Laycock lived long before his day, and his views on this, as on other subjects, are still little known, and seem to have made no impression on those who have since written on Bright's disease. In this connexion another paragraph from Craigie may be quoted. He says: "A singular effect of renal inflammation and suppuration is to induce paraplegia and symptoms of diseased spine. It has been long known that injuries and diseases, chiefly of an inflammatory character, in the spine or spinal cord were liable to be followed by various morbid states of the urinary secretion, which was generally rendered alkalescent or ammoniacal, sometimes deposited the ammoniaco-magnesian phosphate, sometimes the ammonia carbonate. Belingeri had observed that in animals, after experiments on the spinal cord, inflamma. tion was liable to attack the kidneys and the peritoneum, and render the former red and vascular, and cover them with lymph. Mr. Stanley has shown, by a judicious selection of cases, that when the spinal cord is supposed to be diseased or injured either directly or in consequence of disease, or injury of the vertebras, causing pain in the back and paraplegia, the symptoms so produced did not originate from disease either of the vertebrae, the cord, or the membranes, all of which were sound, but from inflammation or. suppuration of the kidneys, in which, in general, were found collections of purulent matter. From such cases it must be inferred, as
Mr. Stanley has done, that disease originating in the kidneys simulates and may give rise to disease in the spinal cord, probably by a reflected influence from the diseased gland through its nerves to those concerned with the spinal cord. It may conversely be inferred that in any morbid state of the spinal cord the impaired influence of the nerves over the renal action, allowing the urine to be secreted in the kidney in an alkaline state, gives rise to a new train of evils by the irritation necessarily induced in the tubular part of the kidney and in the calycine membrane. The ammoniacal urine then irritates, perhaps, both the cortical and tubular part of the glands, and must certainly irritate the calycine membrane, and is the cause of the inflammatory states which it often presents." The italics are mine. Early investigators are apt to put the cart before the horse. Hitherto the profession has had its eye on the kidney, and regard it as a cause of dropsy; but the suggestion made in that quotation that it is the central nervous system that is the primary cause, taken in connexion with the contention of Laycock that the dropsy in kidncy disease was a neurosis, should direct the attention of pathologists, and physicians. as well, to the neurotic theory of all forms of dropsy. In my efforts to spot the primary cause of my many symptoms I am not satisfied when I can merely cure them, I must be able to cause them as well, before I feel absolutely certain that I have reached the true cause, and so far as I have got I feel pretty certain that ere long Laycock's views will be proved to be very near if not the absolute truth. I have discovered that the very ideas we have depend upon the food we eat, and if our physiologists, leaving meantime the study of metabolism which so puzzles them, would direct their attention to the physiological action of our common foods, a much easier subject, they would arm the physician with a weapon which no devil of disease could withstand. Dietetics would then bo studied and taught as it ought to be, disease would disappear, and modern men might live as long as Methuselah is said to have done-I am, etc.,

Hawick, Sept. 7th. John Haddon, M.D.

\section{MODERN METHODS IN THE DIAGNOSIS OF PHTHISIS.}

Sir, - The excellent digest of the above subject. Dr. Clive Riviere gives might be bettered in one respect. Refinements in percussion such as Krönig's topographical method, although making pretty demonstrations upon occasion, seldom-do they?-cause any one to make up his mind about a case, unless he be an exceptional person -a Potain or an Ewart. But the author quoted gives two other wrinkles which, with the number of experts of very junior standing we now have, may be of widespread use. The one, described on p. 665 of the eleventh volume of the twentieth century Deutsche Klinik, Krönig (making the plea "sit venia verbo," for a mongrel word) calls " apicalgia." It is simply tenderness in the apical region to direct, or for the matter of that, indirect percussion. For some time I have thought this a very reliable sign-symptom. The other has to do with auscultation. If you suspect the apex, give a good dose of codeine overnight, and examine for post-tussive râles early next morning, before the secretion is coughed up.-I am, etc.,

Northumberland Sanatorium,

W. C. Rivers.

Barrasford, Eept. 2 nd.

ASSISTANT MEDICAL OFFICERS IN ASYLUMS.

Sir,-In a recent issue of the Journal I see that the asylum medical officer is referred to as a "professional pariah," and that his life is " not a happy one." I have during the past few years had considerable insight into asylum life both as locum and as guest of the medical officers, and in that time have seen and heard sufficient to make me wonder that "An A.M.O.'s" letter was not of a more vituperative and indignant nature. I was surprised and horrificd to find that the condition of the medical officers was in a state of such hopeless stagnation.

I learnt that men of eight and nine years' service were earning a pittance of $£ 250$ a year, this being only $£ 50$ more than the starting salary advertised to-day. It makes one wonder how much men with less ability would be earning in general practice after the same period. But that is not all. Promotion, as "An A.M.O." states mildly, 